\title{
Signal evaluation environment: a new method for the design of peripheral in-vehicle warning signals
}

\author{
Julia Werneke • Mark Vollrath
}

Published online: 7 February 2011

(C) Psychonomic Society, Inc. 2011

\begin{abstract}
An evaluation method called the Signal Evaluation Environment (SEE) was developed for use in the early stages of the design process of peripheral warning signals while driving. Accident analyses have shown that with complex driving situations such as intersections, the visual scan strategies of the driver contribute to overlooking other road users who have the right of way. Salient peripheral warning signals could disrupt these strategies and direct drivers' attention towards these road users. To select effective warning signals, the SEE was developed as a laboratory task requiring visual-cognitive processes similar to those used at intersections. For validation of the SEE, four experiments were conducted using different stimulus characteristics (size, colour contrast, shape, flashing) that influence peripheral vision. The results confirm that the SEE is able to differentiate between the selected stimulus characteristics. The SEE is a useful initial tool for designing peripheral signals, allowing quick and efficient preselection of beneficial signals.
\end{abstract}

Keywords Attention allocation - Visual scan strategies . Driving behaviour $\cdot$ Intersection accidents $\cdot$ Exogenous orienting

Driving is a complex and dynamic task, and successfully driving in traffic requires a large amount of mental resources (Hills, 1980). It is basically dominated by visual attentional demands (Dewar \& Olson, 2002). According to

J. Werneke $(\bowtie) \cdot$ M. Vollrath

Department of Traffic and Engineering Psychology,

TU Braunschweig,

Gaußstraße 23,

38106 Braunschweig, Germany

e-mail: Julia.Werneke@tu-braunschweig.de
Fell (1976), more than $90 \%$ of traffic accidents are due to human errors, and one of the major causes of human errors in traffic is insufficient information (Hills, 1980; Olson, 1993; Sivak, 1996). Following Norman's (1981) classification of errors, this refers to 'slips in the formation of intention'. Reason (1992) called these errors 'mistakes'. To reduce traffic accidents, an understanding of the causes of these information errors is required.

In the 1970s, in various countries a number of 'in-depth', 'on the spot', and 'at the scene' accident studies were conducted to identify accident causations and to provide more detailed information about the circumstances leading to accidents (see, e.g., Clayton, 1971, 1976; Fell, 1976; Sabey \& Staughton, 1975; Staughton \& Storie, 1977; Treat et al., 1979). Almost all of these studies confirmed that one of the major contributory factors to accidents is perceptual error on the part of the driver. Accordingly, a recent indepth accident study about the involvement of human errors in the causation of car accidents in Germany found that in $41.5 \%$ of 775 severe accidents, lack of information was the main cause of the accidents (Vollrath, Briest, \& Drewes, 2006). Similar results were found in the studies of Graab, Donner, Chiellino, and Hoppe (2008), Hoppe, Zobel, and Schlag (2007), and Wierwille and Tijerina (1995). Looking only at intersection accidents, this percentage increases to above 90\% (Hoppe et al., 2007; Vollrath et al., 2006). For that reason, in recent years intersection safety has become increasingly important within the field of advanced driver assistance systems (ADAS). For example, the EU project INTERSAFE (Intersection Safety, 2004-2007) of the integrated project PReVENT was created to generate an overall European approach to support drivers in critical intersection situations, and thus to increase safety at intersections (see, e.g., Fuerstenberg, 2005; Fuerstenberg \& Roessler, 2007). 
In the accident analyses mentioned above, two major reasons for the perceptual errors have been identified. Drivers either reported that they failed to see the other traffic ('looked but failed to see': LBFTS) or that they failed to look, and thus could not see the other traffic (cf. Staughton \& Storie, 1977; see also Hills, 1980; Rumar, 1990). Relatively few studies have shown that these LBFTS errors are very relevant, especially at intersections (see, e.g., Brown, 2005; Cairney \& Catchpole, 1996; Herslund \& Jørgensen, 2003; Hills, 1980; Koustanaï, Boloix, Van Elslande, \& Bastien, 2008; Langham, Hole, Edwards, \& O'Neil, 2002; Sabey \& Staughton, 1975; Staughton \& Storie, 1977). The second kind of error corresponds to an inadequate allocation of the driver's attention. In-depth analyses at intersections have shown that drivers tend to focus their attention on areas where other vehicles with the right of way may come from. As a result, other areas of the intersection are not paid attention to by the drivers. For example, when a driver turns right and a cyclist is coming from the right-hand side on a two-way cycle track, drivers often reported not having noticed the cyclist at all (Pasanen, 1992; Räsänen \& Summala, 1998; Summala, Pasanen, Räsänen, \& Sievänen, 1996).

To avoid this second kind of error, it would be helpful to direct the driver's attention towards these areas that he or she neglects. The question is how to achieve this. One approach could be in-vehicle warning signals located in the driver's peripheral vision, which could use bottom-up processes to attract the driver's attention (see, e.g., Folk \& Remington, 1996; Lauwereyns, 1998; Neumann, 1984; Posner, 1980; Schneider \& Shiffrin, 1977; Theeuwes, 1994). It is well known that attention is captured by certain signals that appear in the peripheral vision. This process is rapid, automatic, and does not involve conscious processing or decisions on the part of the driver. In addition, these kinds of signals do not reduce capacity for performing other tasks (Jonides, 1981; Posner \& Snyder, 1975), which is an important point for driving in complex situations like intersections.

First studies have demonstrated the positive effect of these peripheral visual signals in driving (see, e.g., Henning et al., 2008; Ho \& Spence, 2009; Kienast et al., 2008; Mahlke, Rösler, Seifert, Krems, \& Thüring, 2007). In these studies, LEDs situated at the bottom of the front window of the car (e.g., Henning et al., 2008; Mahlke et al., 2007) or close to the side mirrors (Wolkenstein, 2005) were used. Compared to traditionally designed warning signals, which are mostly presented near the speedometer, these peripheral warnings are capable of disrupting the current attention allocation of the driver and directing his or her attention in the appropriate direction. However, it is still unclear how these signals should be designed in order to capture the driver's attention most effectively, as well as which kind of signal characteristics (e.g., size, colour, onset) are best used to achieve this aim. To test different signals in driving simulators or even in real road traffic is time-consuming and hard to do, since the situations in which they would be needed require extensive programming in driving simulators and are hard to find in real traffic. Additionally, it may be dangerous to test these systems in real traffic, since drivers might be distracted.

For this reason, a relative simple test situation in the laboratory called the Signal Evaluation Environment (SEE) was developed. The basic idea was to create a test situation that both draws on similar resources from the participants and requires attention allocation similar to that required by drivers at intersections (primary task). In this situation, warning signals are introduced, and whether and how fast the participants' attention shifts towards these signals is tested. It is much easier to keep the difficulty of the primary task constant in such a laboratory situation as compared to situations in real traffic. Thus, different signals can be compared in a short time and with low effort with similar task loads for all participants.

The examination of peripheral signals with the SEE method is useful to give a first impression of which peripheral signals could be salient and powerful enough to attract the operator's attention in such dynamic situations. The results can then be used for preselection in early stages of the design process of peripheral warning signals. Thus, the design process of these signals can be executed much faster and more efficiently than by testing all prototypes in a driving simulator or in real road traffic. In later stages of the design process, a validation of the effective stimuli in real traffic situations is, of course, necessary. The SEE is an abstract simulation of driving in complex intersection situations, and thus a rather artificial situation for testing peripheral signals. Results from the SEE method thus should be validated in real traffic. However, this validation of the peripheral signals can focus on a small sample of signals that have been preselected by the SEE.

This article describes the SEE and four experiments conducted to validate the method with regard to its sensitivity to detect differences in signal quality. Previous experiments conducted in the area of attention research have investigated various stimulus characteristics that capture the observer's attention automatically, also known as attentional capture (see Remington, Johnston, \& Yantis, 1992; Theeuwes, 1992, 1994, 2004; Yantis \& Egeth, 1999; Yantis \& Jonides, 1990; for reviews, see Egeth \& Yantis, 1997; Ruz \& Lupiáñez, 2002; Theeuwes \& Godijn, 2001; Yantis, 2000). It has been shown that objects that differ from others with regard to a basic feature are easily perceived (feature singletons; e.g., Pashler, 1988; Theeuwes, 1992; Yantis, 1998). More relevant with regard to warning signals are results showing that an abrupt visual onset is quite effective at capturing attention (e.g., Jonides, 1981; Lambert, Spencer, \& Mohindra, 1987; 
Remington et al., 1992). Here, luminance and the novelty of objects are quite important (e.g., Yantis, 1998; Yantis \& Hillstrom, 1994; Yantis \& Jonides, 1996). In contrast, different shapes are harder to perceive in peripheral vision. Based on these findings, we selected four stimulus characteristics for the validation: size, flashing, colour contrast, and shape. Each of these characteristics was examined in a separate experiment. The first experiment was designed to examine the effect of the size of peripheral stimuli including 12 different stimulus sizes. Based on these results, different colour contrasts (Exp. 2) and shapes (Exp. 3) of the stimuli using two stimulus sizes were varied to examine whether a 'good' stimulus colour contrast or shape can improve attentional capture. In Experiment 4, the flashing of signals was investigated to examine whether slow or fast flashing improves the detection of a peripheral stimulus. We hypothesized that large stimulus sizes, bright colours, and fast flashing of peripheral stimuli should capture the participants' attention better, and thus lead to shorter reaction times. We also hypothesized that the shape of the stimuli would have only a small influence on the reaction time, because peripheral vision is rather weak in distinguishing shapes. However, the shape might be an important dimension for in-vehicle warning signals that could be used to convey information, for example, about the appropriate reaction of the driver in a given situation. This is why the stimulus shape was investigated. In the following sections, the SEE test situation and the four experiments are described.

\section{General method}

\section{Signal evaluation environment}

The overall aim of the development of the SEE was to create an easy-to-learn test situation in the laboratory that is well controlled and requires visual scan processes similar to those found in a complex driving situation at an intersection. With regard to these requirements, a primary and a secondary task were developed. The primary task consists of two subtasks. The first subtask (A) corresponds to a driving situation in which drivers have to monitor two locations and decide whether they can enter the intersection. This is the case, for example, when a driver is approaching a T-shaped intersection from the leg of the $\mathrm{T}$ and has to yield to cars from the right- and left-hand sides. This situation is simulated in the SEE by stimuli appearing at two locations, one at the right and one at the left-hand side. These stimuli consist of random numbers between 1 and 9. Every time a number appears, the operator has to decide whether the number is odd or even. To respond they have to press either a left or a right button. Certainly, the operator's response is not comparable with handling a real car in an intersection. Nevertheless, the basic visual attention processes and the decision task do capture psychological characteristics similar to those in this driving situation. The influence of handling a car on the detection of peripheral stimuli is not examined here. In addition, this subtask also does not simulate the distance estimation required in real traffic when one is deciding whether or not one can enter the intersection. However, the task uses very basic and well-learned decision processes that are done without much conscious reflection, very similar to distance estimation and decision in real traffic.

In the SEE, the number can either appear on the left or the right, with $80 \%$ left and $20 \%$ right stimuli. This is similar to the drivers' attention allocation when the driver turns right at an unsignalised intersection. In-depth surveys of bicycle-car accidents that have analysed the visual scan patterns of the drivers turning right have shown that over half of the drivers' attention was allocated to the left side of the intersection. Only few control gazes to the right-hand side were made by the drivers, mainly when they began to enter the corner of the intersection (see, e.g., Kulmala \& Beilinson, 1991; Summala et al. 1996). The drivers have expectations of where task-relevant information-for instance, cars from the left-hand side-might come from. Thus, they watch this side more frequently. Additionally, their attention is allocated, even though less so, to the right side of the intersection, because this is the direction in which they approach. Therefore, within this first subtask, the participants have to monitor both locations. They have to focus their attention at the location where the next stimulus will appear, and then they have to decide whether it is odd or even. In the first subtask, a new stimulus is given as soon as the participant has entered an answer. If not, a new digit is shown after $2 \mathrm{~s}$, and this is recorded as a 'missing reaction'. Figure 1 shows a screen shot of the SEE and its tasks.

In addition, a second subtask (B) was added. At the top left, an ' 8 ' made of boxes is always present, but changes after a certain time to a ' 6 '. This is a quite subtle change that does not

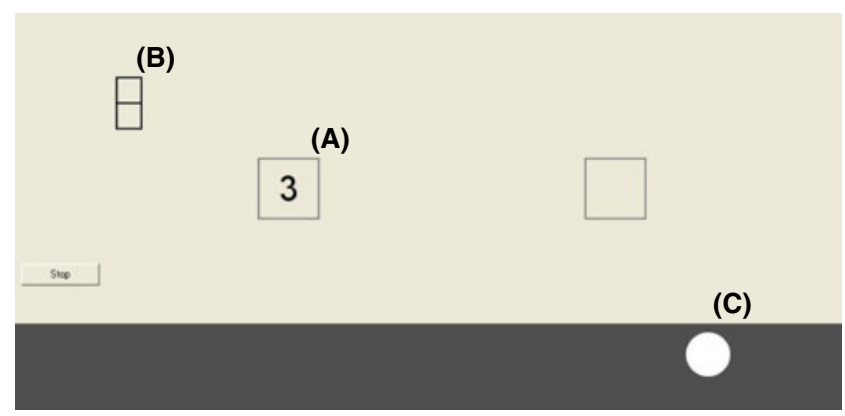

Fig. 1 Screen shot of the SEE with its tasks: (A) first subtask, (B) second subtask, and $(C)$ peripheral stimulus (here, a white circle) 
attract the participants' attention (disappearance of a part of the ' 8 '). Thus, the participants have to monitor this location as well, by looking there from time to time without neglecting the first subtask. The frequency of changes is much lower for this subtask than for the first one. In the second subtask, a ' 6 ' appears an average of every $9.4 \mathrm{~s}$. The ' 6 ' is then visible for a maximum of $4 \mathrm{~s}$. When the participant presses the appropriate key, the ' 6 ' changes back to the ' 8 ', but if no reaction occurs within the $4 \mathrm{~s}$, this is considered as a miss and the ' 8 ' appears again. The idea of this second subtask is to provide another location where something relevant might happen. In real road traffic, this corresponds to looking for other traffic participants, such as pedestrians and cyclists at the intersection. Usually these road users appear less frequently than cars, but at least before entering the intersection, the driver should check once whether any such road users are present.

Using these two subtasks, the operator's attention is focused and allocated in a manner very similar to when waiting to enter an intersection. When the participants are deeply involved in this situation (between 36 and $45 \mathrm{~s}$ after the start of the subtasks), the test stimulus (C) is presented at the bottom right of the screen within a dark grey crossbar. In this study, all stimuli were presented only as projections. However, real warning signals such as small lamps or displays placed within the operator's reach are also possible to implement in the SEE. This was not examined here, however. The crossbar at the bottom of the screen is designed to resemble the instrument panel of a car. The participants are instructed to react as fast as possible as soon as the stimulus appears. They are also instructed to focus their attention only on the first subtask and not the dark crossbar, even though this instruction is barely required. Pretests confirmed that the other two subtasks effectively captured the participants' attention. Additionally, the analysis of both subtasks didn't show extremely long reaction times or numerous misses. Thus, even without controlling the experiment by means of recording gaze behaviour, this design ensures that the participants process the test stimuli only with peripheral attention. The peripheral stimulus is visible until the participant reacts by pressing the appropriate button on the keyboard. If the participant responds, the stimulus disappears, and after an average of approximately $40 \mathrm{~s}$ a new stimulus is presented. If the stimulus is not detected, the stimulus is visible until the end of the trial. On average, four stimuli are presented in one trial.

For presenting the SEE, a large screen is used $(194 \times$ $145 \mathrm{~cm}$ ). Figure 2 gives a lateral view of the laboratory apparatus. The participants are seated approximately $1 \mathrm{~m}$ in front of the screen (A) at a table (B), where the keyboard for the reactions is located. The picture of the SEE is presented via a video projector (C) using an $860 \mathrm{H}$ lamp. In this situation, the display corresponds to a visual angle of

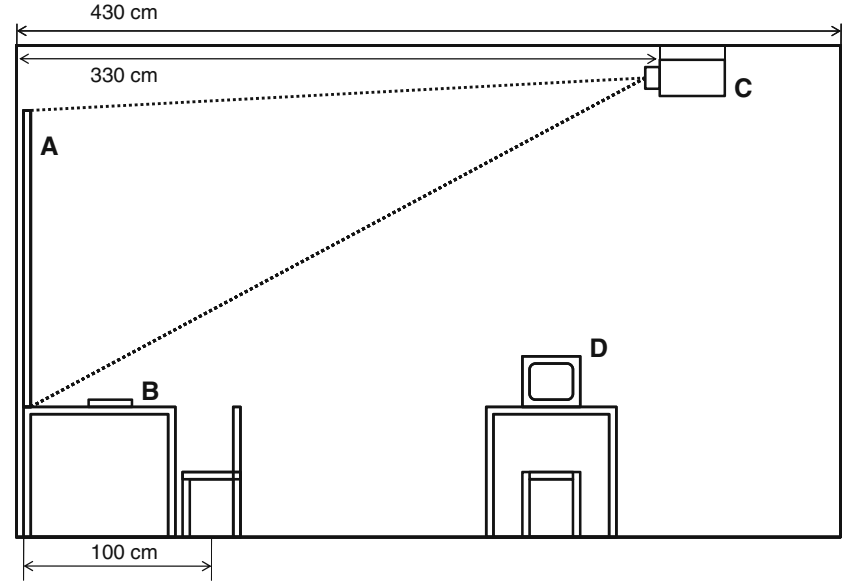

Fig. 2 Lateral view of the laboratory apparatus: (A) screen, (B) table with keyboard, (C) video projector, and (D) data recording

approximately $57^{\circ}$ (vertical) by $87^{\circ}$ (horizontal) from the participants' seat position. This is very similar to the situation of the driver in the front seat of a car when he or she is looking out of the windscreen. The projection has a resolution of $1,024 \times 768$ pixels. The figure ' 8 ' or ' 6 ' is presented $17^{\circ}$ to the left of the left square and $54^{\circ}$ to the left of the right square of the first subtask (see Fig. 1). The location of the peripheral stimuli is fixed approximately $50^{\circ}$ from the left square because the stimuli appear only by defining numbers in the left square. This is similar to a position in the middle console inside a real car. During the whole experiment, the room light is switched off.

All reactions in our experiments were captured by using a labelled keyboard. The ' $\mathrm{W}$ ' and ' $\mathrm{O}$ ' keys were used for the odd and even reactions, respectively (first subtask of the primary task). They were labelled as a red and a green button. For the more sporadic change of the ' 8 ' to a ' 6 ', the participants had to press the ' 1 ' key (labelled as a white button) as soon as they noticed the change (second subtask of the primary task). Finally, the space bar was used to indicate that the test stimulus had been noticed (secondary task).

Each trial was used to assess reactions to one of the peripheral stimuli. During one trial, the stimulus appeared approximately four times in about $3 \mathrm{~min}$. Thus, in a very short time it was quite possible to investigate a large number of different signals that could be compared with regard to how adequately and quickly participants detected them and reacted accordingly. Objectively, reaction times in milliseconds and the number of misses (if any) for the stimuli were recorded. If the space bar was pressed without a peripheral stimulus in the crossbar, no response was given. In the four experiments, none of the participants pressed the space bar without the appearance of a peripheral stimulus. Additionally, reaction times and misses for the two subtasks were recorded, but were analysed only to 
ensure that the participants were really engaged in the two subtasks of the primary task. Over all four experiments, the analysis of both subtasks showed no longer reaction times or any numerous misses. Thus, for the four experiments one can assume that the participants processed the peripheral stimuli only with their peripheral attention.

For each stimulus and participant, the median reaction time was computed as a measure of the effectiveness of the stimulus to capture attention. Reaction times larger than $3,000 \mathrm{~ms}$ were excluded as outliers, and it was assumed that they were not due to automatic attention allocation by the participant. There was one signal in Experiment 1 for which 3 out of 5 participants had longer reaction times. We concluded that this stimulus was very hard to see and clearly not suited to capture the observer's attention. For the other signals in all four experiments, only very few outliers occurred. Lack of concentration or a changing priority in handling the primary and secondary tasks of the SEE could be the reason for that. These outliers were excluded, as the reaction times were clearly not typical for the situation. Since each participant received all different stimuli, the experiments were analysed by within-subjects ANOVAs for the median reaction times, using post-hoc pairwise comparisons to examine which stimuli differed from each other. Because this was done only to get a better picture of where the differences occurred, these post-hoc pairwise comparisons were not Bonferroni corrected, but a significance level of .05 was used. When two stimulus characteristics were examined together in one experiment, two-way ANOVAs were accordingly used. Significant interactions between two stimulus characteristics were analysed using $t$ tests for dependent samples to compare pairs of stimuli. Each ANOVA had a significance level of .05. Results were corrected for sphericity violations where necessary by use of the Greenhouse-Geisser modification (Greenhouse \& Geisser, 1959).

\section{Stimulus characteristics}

The SEE was used to assess the efficiency of different peripheral stimuli with regard to four dimensions: size, colour contrast, shape, and flashing. These main dimensions were chosen for the manipulations because it could be assumed that they differed in the perceptual processes they activated. The aim of the four experiments was to demonstrate the sensitivity of the SEE to differentiate between stimuli, and thus to validate the method. Additionally, the four main stimulus characteristics were basic categories for the design of visual stimuli, and thus are important for visual in-vehicle warning signals. Another important stimulus dimension was the position of the peripheral stimuli. This dimension was not examined in this study. Four experiments were conducted to examine each of the four dimensions, and the procedure was identical for each of them.

\section{Participants}

In the four experiments, mainly small and age homogeneous samples were used. This was done to ensure that the participants were comparable and that individual differences, such as in age, did not affect the results. Overall, the participants were on average 25.3 years old $(S D=5.9$ years $)$ and mainly female (6 male and 16 female). No participant had dyschromatopsia, and none took part in more than one of the four experiments. The participants were recruited through an advertisement at the campus of TU Braunschweig and in local supermarkets. Most of them were students at TU Braunschweig. The separate samples are described, respectively, in the sections for the separate experiments.

\section{Procedure}

At the beginning of each experiment, the participants provided some socio-demographic information-for instance, age, gender, use of visual aids, and right- or lefthanded. A written instruction was then given out and explained. The participants were briefed on the buttons on the keyboard for reacting to each of the three tasks. All participants were instructed to wear their own glasses if necessary to ensure normal vision. Next, the participants were trained in the different tasks, first one at a time, and then combined. This training lasted for about $15 \mathrm{~min}$. After the training session, the experiment began. In each trial, one stimulus was presented as described above. The different stimuli in one experiment were given in random order. During the whole procedure, the investigator stayed in the room. Depending on the number of the experimental trials, the experiment lasted between 45 and $60 \mathrm{~min}$. All students received test hours for their participation in the study.

\section{Experiment 1: Size}

\section{Aim and participants}

Experiment 1 was conducted to examine the effect of the size of a peripheral stimulus. Different stimulus colours (blue, grey, yellow, green, and red) were used in order to ensure that the results were valid for different colours. However, the effect of colour was not systematically examined in this first experiment, but was done in the second experiment instead (see Exp. 2).

Five female participants were included in the experiment, ranging in age from 24 to 37 years $(M=28.2$ years, $S D=5.2$ years). Three of the 5 participants needed visual 


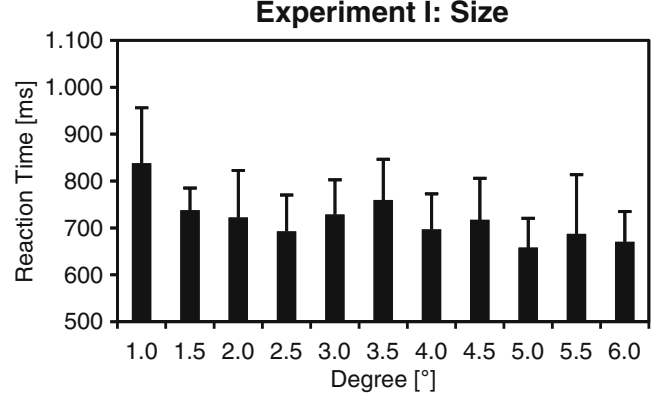

Fig. 3 Means (bars) and standard deviations (lines) of the median reaction times for the 11 sizes of stimuli in Experiment 1

aid to ensure normal vision. The stimulus was a filled circle varying in size between approximately $0.5^{\circ}$ and $6.0^{\circ}$, in steps of $0.5^{\circ}$. On the enhanced screen, this corresponded to sizes between 1.0 and $11.4 \mathrm{~cm}$. The sizes were presented in random order.

Results

First of all, the smallest stimulus, of $0.5^{\circ}$, could not be included in the analysis of the reaction times because 3 of the 5 participants did not see the stimulus. Thus, even without a statistical analysis, it is clear that this stimulus size was not useful. For the remaining sizes, a significant main effect was found, $F(10,40)=2.99, p=.007$. Figure 3 shows the reaction times in milliseconds for the 11 sizes of stimuli.

As Fig. 3 demonstrates, the longest reaction time was found for the smallest size, $1.0^{\circ}(M=838 \mathrm{~ms}, S D=119 \mathrm{~ms})$. As the post-hoc pairwise comparisons showed, this was significantly slower as compared to all of the stimuli of $4.0^{\circ}$ and larger. Here, the significances of the post-hoc tests lay between $p=.010$ and $p=.028$. The participants responded in an average of $686 \mathrm{~ms}(S D=84 \mathrm{~ms})$ to the stimuli of $4.0^{\circ}$ and larger. Additionally, the reaction time to the $1.0^{\circ}$ stimuli was significant slower as compared to reaction times to the stimuli of $2.0^{\circ}(p=.004)$ and $2.5^{\circ}(p=.028)$. Between the stimuli of $4.0^{\circ}$ and larger, as well as between the stimuli of $1.5^{\circ}$ and $3.0^{\circ}$, there were no significant differences. In summary, the results show that very small stimuli could not be seen at all or could hardly be seen $\left(0.5^{\circ}\right.$ and $\left.1.0^{\circ}\right)$. In contrast, the larger stimuli, between $4.0^{\circ}$ and $6.0^{\circ}$, were easier to perceive in the periphery. The participants responded significantly faster to these stimuli.

\section{Experiment 2: Colour contrast}

Aim and participants

In Experiment 2, five different hues of peripheral stimuli were used on a dark grey background colour (Fig. 1): blue, green, red, white, and grey. All hues had their maximum saturation and brightness, except for the grey. Additionally, a very small $\left(1.0^{\circ}: 1.9 \mathrm{~cm}\right.$ on the screen $)$ and a large $\left(5.0^{\circ}\right.$ : $9.5 \mathrm{~cm}$ on the screen) filled circle stimulus were used in order to examine whether the difficulties in perceiving the very small stimulus could be improved by displaying it in a colour with a high contrast to its background.

The experiment had a 5 (colour contrast) $\times 2$ (size) within-subjects design. The order of the five colour contrasts per size was counterbalanced according to a Latin-square design. The order of the two sizes was randomized, with participants beginning either with the smaller or the larger stimulus. Thus, order effects were controlled.

Five female participants took part in this experiment. They ranged in age from 21 to 36 years, with an average age of 26.4 years $(S D=7.1$ years). Three of the 5 participants used visual aid during the experiment to ensure normal vision.

Results

There were significant main effects of colour contrast $[F(4$, $16)=5.78, p=.004]$ and size $[F(1,4)=20.08, p=.011]$. Additionally, there was a significant colour contrast $\mathrm{x}$ size interaction $[F(4,16)=4.86, p=.009]$. Figure 4 shows the results. Reaction times were slower for the smaller grey $(M=986 \mathrm{~ms}, S D=194 \mathrm{~ms})$ and $\operatorname{red}(M=1,170 \mathrm{~ms}, S D=$ $359 \mathrm{~ms}$ ) stimuli, as compared to the larger stimuli (grey: $M=706 \mathrm{~ms}, S D=36 \mathrm{~ms}$; red: $M=692 \mathrm{~ms}, S D=98 \mathrm{~ms}$ ).

The delay in reactions for both the grey and the red stimuli was significantly stronger for the smaller stimuli as compared to the larger ones [grey: $t(4)=3.78$, $p=.019$; red: $t(4)=2.83, p=.047]$. Thus, a disadvantage for the small stimuli of $1.0^{\circ}$ was only found for the grey and red colours. When the stimuli appeared in green, white, or blue, the small stimuli could be reacted to as fast as the larger stimuli [green: $t(4)=0.90, p=.419$; white:

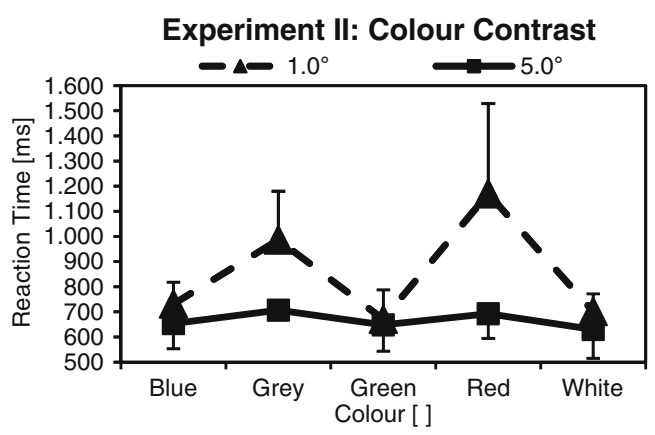

Fig. 4 Means (horizontal lines) and standard deviations (vertical lines) of the median reaction times for the five colours and two sizes of the stimuli in Experiment 2 
$t(4)=1.56, p=.195$; blue: $t(4)=1.78, p=.149]$. The participants responded on average to the green stimuli in $659 \mathrm{~ms}(S D=111 \mathrm{~ms})$, to the white stimuli in $666 \mathrm{~ms}(S D=$ $96 \mathrm{~ms})$, and to the blue stimuli in $692 \mathrm{~ms}(S D=93 \mathrm{~ms})$.

\section{Experiment 3: Shape}

Aim and participants

Experiment 3 examined different shapes of the peripheral stimuli. Reaction times for the filled circle from the first two experiments were compared with those for two arrows: one pointing to the right, and one pointing up (see Fig. 5). The size of the two arrows was chosen in such a way that their area was comparable to that of the circle. All three shapes were again used in two sizes, corresponding to $1.0^{\circ}$ and $5.0^{\circ}$ (circle: 1.9 and $9.5 \mathrm{~cm}$ ). The arrows pointing to the right and up were chosen for this manipulation because these shapes are commonly used in in-vehicle signals - for example, to visualize the driving direction. All stimuli were presented in red in order to eliminate a ceiling effect (see the results of Exp.2) and to examine whether the difficulties in perceiving the red stimulus could be improved by a 'good' shape. In a 3 (shape) $\times 2$ (size) within-subjects design, each participant received each of the six stimuli in one of six experimental trials. The order was counterbalanced according to a sequential balance Latin square to control for order effects.

Six subjects (3 men, 3 women) participated in the experiment. They ranged in age from 20 to 35 years, with an average age of 24.8 years $(S D=7.1$ years). Two participants needed visual aid for normal vision.

Results

The analyses found neither a main effect of shape $[F(2,10)=$ $0.10, p=.906]$ nor an interaction of shape $\mathrm{x}$ size $[F(2,10)=$ $0.31, p=.744]$. However, a comparable main effect of size was found $[F(1,5)=9.26, p=.029]$, as in Experiment 2 . Figure 6 shows the results.

From the reaction times, it is obvious that the participants reacted faster to the larger stimuli. They responded in an average of $723 \mathrm{~ms}(S D=120 \mathrm{~ms})$ to the stimuli of $5.0^{\circ}$ and in $856 \mathrm{~ms}(S D=126 \mathrm{~ms})$ to the $1.0^{\circ}$ stimuli. For all three stimulus shapes, the shape did not affect reaction times $(M=790 \mathrm{~ms}, S D=123 \mathrm{~ms})$.

Fig. 5 The shapes of the stimuli in Experiment 3

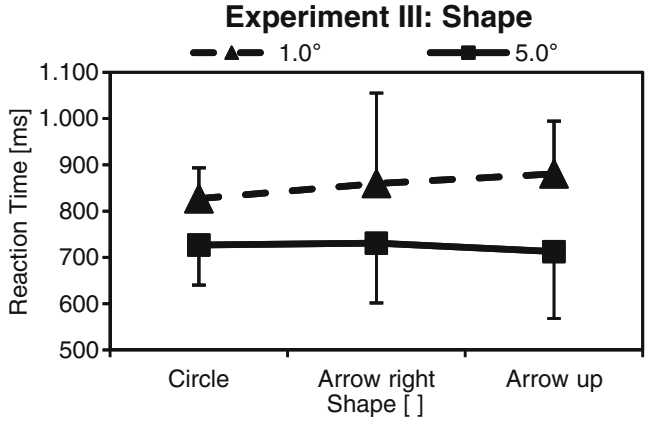

Fig. 6 Means (horizontal lines) and standard deviations (vertical lines) of the median reaction times for the three shapes and two sizes of the stimuli in Experiment 3

\section{Experiment 4: Flashing}

Aim and participants

In Experiment 4, we examined whether the flashing of a peripheral stimulus would improve reaction times. In line with this aim, the red circle was again used in the same two sizes as in Experiment 2. Additionally, the stimuli were presented at three levels of flashing: an abrupt onset without flashing, slow flashing of $1.7 \mathrm{~Hz}$ (alternating between $300 \mathrm{~ms}$ on and $300 \mathrm{~ms}$ off), and fast flashing of $5.0 \mathrm{~Hz}(100 \mathrm{~ms}$ on and off). Thus, the experiment used a 3 (flashing) $\times 2$ (size) within-subjects design. The order of the six experimental trials was counterbalanced according to a sequential balance Latin square. The assignment of participants to trial orders was randomised.

Six participants ( 3 men, 3 women) were included in the experiment. On average, they were 22.5 years old $(S D=$ 4.1 years). Four of the participants wore visual aids during the experiment.

\section{Results}

There was no significant main effect of flashing $[F(2,10)=$ $0.36, p=.589]$, nor a significant flashing $\mathrm{x}$ size interaction $[F(2,10)=0.56, p=.590]$. However, as in the previous experiments, a significant main effect of size was found $[F(1,5)=28.33, p=.003]$. Figure 7 shows the means and standard deviations of the median reaction times.

At all flash intervals, the participants reacted faster to the larger stimuli $(M=688 \mathrm{~ms}, S D=83 \mathrm{~ms})$ as compared to the smaller ones $(M=891 \mathrm{~ms}, S D=178 \mathrm{~ms})$. Flashing did not substantially alter the reaction times. The reaction times for the smaller stimuli seemed to be somewhat shorter with a flashing stimulus as compared to a stimulus that was only an abrupt onset, but the difference was not significant. The participants responded to the smaller stimuli with a flashing of $5.0 \mathrm{~Hz}$ in an average of $876 \mathrm{~ms}(S D=152 \mathrm{~ms})$ and with a flashing of $1.7 \mathrm{~Hz}$ in an average of $872 \mathrm{~ms}(S D=$ 


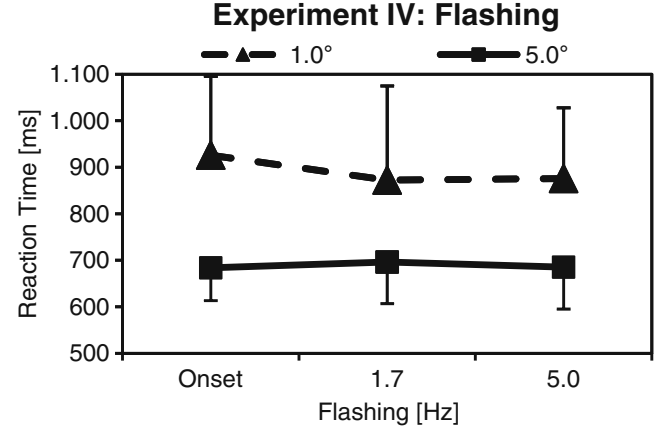

Fig. 7 Means (horizontal lines) and standard deviations (vertical lines) of the median reaction times for the three flashing conditions and the two sizes of the stimuli in Experiment 4

$203 \mathrm{~ms})$. On average, they needed $926 \mathrm{~ms}(S D=169 \mathrm{~ms})$ to recognize the smaller stimuli without flashing (onset).

\section{Summary and discussion}

The goal of this study was to develop an experimental setting in the laboratory, called the Signal Evaluation Environment (SEE), that would enable efficient testing of different peripheral in-vehicle warning signals. Four experiments were conducted to examine the validity of the SEE using four stimulus characteristics (size, colour contrast, shape, and flashing). The SEE was shown to be an effective method for assessing the effectiveness of different stimulus properties at attracting an observer's attention when presented in peripheral vision. Thus, the SEE method provides a useful initial step in the design process of peripheral signals for complex domains, such as driving.

The aim of the SEE was to create a laboratory test situation which would require visual-cognitive processes and a range of vision similar those required at intersections, in order to accurately evaluate the efficiency of peripheral signals. Moreover, with the SEE method, statements could be made about how fast different stimulus properties captured the observer's attention. Compared to research in simulators or real road-traffic conditions, the SEE is well controlled and easy to learn. Additionally, the attention focus of the participants can be controlled easily. Pretests showed that the two subtasks of the primary task captured the participants' attention effectively. Thus, no eye-tracking system was needed to control the gaze behaviour of the participants to ensure that they processed the peripheral stimuli only with their peripheral vision. Consequently, it was possible to evaluate in a standardized situation a variety of peripheral signals in a relative short time and with low effort. Overall, the SEE is an effective method to use as a preselection method for peripheral warning signals in complex domains such as driving. Thus, the design process of those signals can be executed much faster and more efficiently than by testing all prototypes in a driving simulator or in real road traffic.

Additionally, the stimuli implemented in the SEE can be designed easily using any graphic program that is able to export JPEG files, such as Photoshop or even PowerPoint or Excel. It is also possible to implement changes in the stimuli such as the flashing used in Experiment 4. Furthermore, one could use real signals such as small lamps (e.g., LED-band [see Mahlke et al., 2007] or LED-matrix [see Henning et al., 2008]) or displays that are placed at a location near the observer's reach or near the enhanced screen.

The participants can be trained in approximately $15 \mathrm{~min}$, and it takes about 3 min per participant to measure valid reaction times for one signal only. Small samples of 5 motivated participants are sufficient to find statistically significant differences. The equipment required for the test is just a computer and a video projector.

Nevertheless, some limitations of the SEE method should be noted: First, the stimulus characteristics and the position of the stimuli provided on the enhanced screen are not identical to the situation in a real car. Also, the participants sit approximately $1 \mathrm{~m}$ from the screen on which the peripheral stimuli occur, whereas in-vehicle signals are mostly placed within the driver's reach-for instance, in the cockpit panel, at the bottom of the front window (see, e.g., Henning et al., 2008; Kienast et al., 2008; Mahlke et al., 2007), or close to the side mirror (Wolkenstein, 2005). In future evaluation studies, real warning signals or displays placed near the observer should be used. Second, the primary tasks of the SEE use only 2-D static projections. Thus, the tasks do not simulate the distance estimation required in real road traffic. Third, with the SEE method, only large effects could be detected, due to the sample size used in the experiments. Signal characteristics that influence reaction times consistently but only in a small way would not be detected. However, since the SEE method is used for the design of efficient peripheral signals, one would only be interested in strong effects that really work to attract the driver's attention. This is a different case from the basic attention research mentioned above, where even minimal changes in reaction times are interesting because they reflect different levels of cognitive and attentional processes. Finally, the illumination of the laboratory room is probably not identical to the situation in a real car. Overall, the SEE method can be used to find out which peripheral signals seem to be well or badly suited to capturing the operator's attention, but there is no guarantee that the signal that was better in the laboratory will be good in the real world. Thus, it does not completely replace driving-simulator or real driving studies.

Four experiments were conducted to validate the SEE method with regard to its sensitivity to detect differences in 
the effectiveness of different stimulus characteristics in peripheral vision. Based on the findings from the earlier attention studies mentioned above, the main characteristics that were chosen for manipulation were size, colour contrast, shape, and flashing. Each of these characteristics was examined in a separate experiment. The results of the experiments confirmed that the SEE was able to differentiate between the quality of these stimulus properties. Thus, large stimulus sizes and bright colours led to shorter reaction times and captured the participants' attention better than very small and dull stimuli (Exps.1 and 2). Furthermore, it was confirmed that the shape of peripheral stimuli had hardly any effect on peripheral vision (Exp. 3). With regard to flashing, there was no improvement in the participants' reaction times (Exp. 4). This was somewhat surprising at first, because it is well known that abrupt changes attract an observer's attention. One should note that even the simple circle in Experiment 4 that did not flash had an abrupt onset, to which the participants probably reacted. Thus, one could argue that the one abrupt onset was sufficient, provided that the signal was large and bright enough. Furthermore, in all four experiments all stimuli were presented only as projections on the enhanced screen. Compared to real in-vehicle warning signals, such as small lamps and displays, they were high-power sources of light and emitted strongly coloured light with a higher lumen output. This could have influenced the results presented here, and should be investigated in future evaluation studies. With regard to size, colour contrast, and shape, the SEE clearly confirmed that different stimulus characteristics influence perception in certain ways. Therefore, the SEE is an effective method for assessing the effectiveness of different stimulus characteristics to attract an observer's attention when presented in peripheral vision.

Some limitations of the four experiments should be noted: First, the number of participants used was small. Thus, the results are not representative for the whole population of drivers. For example, it might be that older drivers would require even larger signals for them to be effective. Thus, these results should be confirmed with different subsamples of drivers. On the other hand, when examining the properties of peripheral signals, one is concerned with very basic perceptual processes that have a strong physiological foundation (see Eysenck, 2004; Proctor \& Van Zandt, 2008; and Woodson \& Conover, 1964, to mention just a few). These processes should be very similar in different people. In fact, very few participants $(n=5)$ should be sufficient to find a significant effect, because all react in a very similar way. Second, the samples we used were homogeneous in age to ensure that the participants were comparable and that individual differences did not affect the results. Nevertheless, the results of Experiments 2 and 3 showed different reaction times for the small red circle (Exp. 2, 1,170 ms; Exp. 3, $827 \mathrm{~ms}$ to these stimuli). Individual differences could be the reason for these large discrepancies. In Experiment 2, all participants were female. In contrast, in Experiment 3 the genders were balanced. Future studies with both larger and heterogeneous samples should be conducted to examine the potential influence of such individual differences as age and gender on the detection of peripheral stimuli. Finally, in all four experiments, the peripheral stimuli were presented approximately $50^{\circ}$ from the observers' foveal vision, which is quite far away. Another important stimulus dimension to manipulate could be the position of the stimuli in the participants' peripheral field of view. One might expect that the location of the stimuli could have an effect on their perception.

From our point of view, the SEE is a useful initial tool for designing peripheral signals, allowing for quick and efficient preselection of beneficial signals. The SEE represents a wellcontrolled method as a first step in the design process of invehicle warning signals. With relatively low effort, a test situation similar in visual-cognitive demands to driving at intersections was constructed to evaluate the effectiveness of warning signals before testing them in complex simulation scenarios or real roads. Results using the SEE method give a first impression of how peripheral signals should be designed to be salient enough to attract observers' attention in such dynamic situations. Because of the simple experimental setup, the SEE method could be useful for testing various signals in order to develop guidelines for the optimal design of peripheral signals that will attract an observer's attention effectively. Thus, the SEE facilitates preselection from a range of different peripheral stimuli. Of course, due to the rather artificial setup, the validity of the SEE method and the efficiency of its results for real-world driving have to be proven in a simulator or in real road-traffic situations. The validity of the peripheral signals can be focused on by using a small sample of signals that have been pre-selected via the SEE. With the SEE method, the design and evaluation stages for effective warning signals can clearly be reduced, leading to only efficient signals that will attract observers' attention best being tested in simulation studies, and afterwards in real cars. Thus, time and effort can be substantially reduced.

Acknowledgement The SEE software can be obtained free of charge from Julia Werneke (Julia.Werneke@tu-braunschweig.de) or Mark Vollrath (Mark.Vollrath@tu-braunschweig.de).

\section{References}

Brown, I. D. (2005). Review of the 'Looked but failed to see' accident causation factor (Road Safety Research Report No. 60). London: U.K. Ministry of Transport.

Cairney, P., \& Catchpole, J. (1996). Patterns of perceptual failures at intersections of arterial roads and local streets. In A. G. Gale, I. D. Brown, C. M. Haslegrave, \& S. P. Taylor (Eds.), Vision in vehicles $V$ (pp. 87-94). Amsterdam: Elsevier. 
Clayton, A. B. (1971). Road user errors and accident causation. In Proceedings of the 17th International Congress of Applied Psychology, Liege, Belgium.

Clayton, A. B. (1976). Perceptual and visual factors in the causation of road accidents. In Proceedings of the First International Congress on Vision and Road Safety. Linas: Prevention Routiere Internationale.

Dewar, R. E., \& Olson, P. L. (2002). Human factors in traffic safety. Tucson: Lawyers \& Judges.

Egeth, H. E., \& Yantis, S. (1997). Visual attention: Control, representation, and time course. Annual Review of Psychology, 48, 269-297.

Eysenck, M. W. (2004). Psychology: An international perspective. Hove: Psychology Press.

Fell, J. C. (1976). A motor vehicle accident causal system: The human element. Human Factors, 18, 85-94.

Folk, C. L., \& Remington, R. W. (1996). When knowledge does not help: Limitations on the flexibility of attentional control. In A. F. Kramer, M. G. H. Coles, \& G. D. Logan (Eds.), Converging operations in the study of visual selective attention (pp. 271295). Washington, DC: American Psychological Association.

Fuerstenberg, K. (2005). New European approach for intersection safety: The EC-Project INTERSAFE. In Proceedings of the 5th ITS Europe, Hanover, Germany.

Fuerstenberg, K., \& Roessler, B. (2007). Intersection driver assistance system: results of the EC-Project INTERSAFE. In Proceedings of the IEEE Intelligent Vehicles Symposium, Istanbul, Turkey.

Graab, B., Donner, E., Chiellino, U., \& Hoppe, M. (2008). Analyse von Verkehrsunfällen hinsichtlich unterschiedlicher Fahrerpopulationen und daraus ableitbarer Ergebnisse für die Entwicklung adaptiver Fahrerassistenzsysteme. In TU München \& TÜV Süd Akademie GmbH (Eds.), Conference: Active Safety Through Driver Assistance. München.

Greenhouse, S. W., \& Geisser, S. (1959). On methods in the analysis of profile data. Psychometrika, 24, 95-112.

Henning, M. J., Kienast, H., Lindner, P., Weigel, H., Krems, F. J., Spanner-Ulmer, B., \& Wanielik, G. (2008). Multifunktionale Mensch-Maschine-Schnittstelle. In M. Maurer \& C. Stiller (Eds.), Tagungsband des 5. Workshops Fahrerassistenzsysteme FAS 2008 Universität Karlsruhe (pp. 151-158). Karlsruhe: fmrt e.V.

Herslund, M.-B., \& Jørgensen, N. (2003). Looked-but-failed-to-seeerrors in traffic. Accident Analysis and Prevention, 35, 885-891.

Hills, B. L. (1980). Vision, visibility, and perception in driving. Perception, 9, 183-216.

Ho, C., \& Spence, C. (2009). Using peripersonal warning signals to orient a driver's gaze. Human Factors, 51, 539-556.

Hoppe, M., Zobel, R., \& Schlag, B. (2007). Identifikation von Einflussgrößen auf Verkehrsunfälle als Grundlage für die Beurteilung von Fahrerassistenzsystemen am Beispiel von Kreuzungsunfällen. In VDI Wissensforum (Ed.), Fahrer im 21. Jahrhundert. Human Machine Interface (pp. 121-137). Düsseldorf: VDI.

Jonides, J. (1981). Voluntary versus automatic control over the mind's eye's movement. In J. Long \& A. Baddeley (Eds.), Attention and performance $I X$ (pp. 187-203). Hillsdale: Erlbaum.

Kienast, H., Lindner, P., Weigel, H., Henning, M. J., Krems, J. F., Wanielik, G., \& Spanner-Ulmer, B. (2008). Aufmerksamkeitssteuerung durch räumlich gerichtete Anzeigen in Fahrerassistenzsystemen. In Wissensforum (Ed.), Integrierte Sicherheit und Fahrerassistenzsysteme (pp. 413-423). Düsseldorf: VDI

Koustanaï, A., Boloix, E., Van Elslande, P., \& Bastien, C. (2008). Statistical analysis of 'looked-but-failed-to-see' accidents: Highlighting the involvement of two distinct mechanisms. Accident Analysis and Prevention, 40, 461-469.

Kulmala, R., \& Beilinson, L. (1991). Bicyclist safety at junctions. In Proceedings of the 4th Workshop of ICTCT, Vienna, Austria.
Lambert, A., Spencer, E., \& Mohindra, N. (1987). Automaticity and the capture of attention by a peripheral display change. Current Psychological Research and Reviews, 6, 136-147.

Langham, M., Hole, G., Edwards, J., \& O’Neil, C. (2002). An analysis of 'looked but failed to see' accidents involving parked police vehicles. Ergonomics, 45, 167-185.

Lauwereyns, J. (1998). Exogenous/endogenous control of space-based/ object-based attention: Four types of visual selection? European Journal of Cognitive Psychology, 10, 41-74.

Mahlke, S., Rösler, D., Seifert, K., Krems, J. F., \& Thüring, M. (2007). Evaluation of six night vision enhancement systems: Qualitative and quantitative support for intelligent image processing. Human Factors, 49, 518-531.

Neumann, O. (1984). Automatic processing: A review of recent findings and a plea for an old theory. In W. Prinz \& A. F. Sanders (Eds.), Cognition and motor processes (pp. 255-293). Berlin: Springer.

Norman, D. A. (1981). Categorization of action slips. Psychological Review, 88, 1-15.

Olson, P. L. (1993). Vision and perception. In B. Peacock \& W. Karwowski (Eds.), Automotive ergonomics (pp. 161-183). London: Taylor \& Francis.

Pasanen, E. (1992). The problem of right-turning drivers with cyclists coming from right (Report L4). Helsinki: Traffic Planning Department.

Pashler, H. (1988). Cross-dimensional interaction and texture segregation. Perception \& Psychophysics, 43, 307-318.

Posner, M. I. (1980). Orienting of attention. The Quarterly Journal of Experimental Psychology, 32, 3-25.

Posner, M. I., \& Snyder, C. R. R. (1975). Attention and cognitive control. In R. L. Solso (Ed.), Information processing and cognition: The Loyola Symposium (pp. 55-85). Hillsdale: Erlbaum.

Proctor, R. W., \& Van Zandt, T. (2008). Human factors in simple and complex systems (2nd ed.). Boca Raton: CRC Press.

Räsänen, M., \& Summala, H. (1998). Attention and expectation problems in bicycle-car collisions: An in-depth study. Accident Analysis and Prevention, 30, 657-666.

Reason, J. (1992). Human error. Cambridge: Cambridge University Press

Remington, R. W., Johnston, J. C., \& Yantis, S. (1992). Involuntary attentional capture by abrupt onsets. Perception \& Psychophysics, $51,279-290$

Rumar, K. (1990). The basic driver error: Late detection. Ergonomics, $33,1281-1290$.

Ruz, M., \& Lupiáñez, J. (2002). A review of attentional capture: On its automaticity and sensitivity to endogenous control. Psicológica, 23, 283-309.

Sabey, B. E., \& Staughton, G. C. (1975). Interacting roles of road environment, vehicle and road user in accidents. London: In Proceedings of the Fifth International Conference of the International Association for Accident and Traffic Medicine.

Schneider, W., \& Shiffrin, R. M. (1977). Controlled and automatic human information processing: 1. Detection, search, and attention. Psychological Review, 84, 1-66.

Sivak, M. (1996). The information that drivers use: Is it indeed $90 \%$ visual? Perception, 25, 1081-1089.

Staughton, G. C., \& Storie, V. J. (1977). Methodology of an in-depth accident investigation survey (TRRL Laboratory Report 762). Crowthorne: Transport and Road Research Laboratory.

Summala, H., Pasanen, E., Räsänen, M., \& Sievänen, J. (1996). Bicycle accidents and drivers' visual search at left and right turns. Accident Analysis and Prevention, 28, 147-153.

Theeuwes, J. (1992). Perceptual selectivity of color and form. Perception \& Psychophysics, 51, 599-606. 
Theeuwes, J. (1994). Endogenous and exogenous control of visual selection. Perception, 23, 429-440.

Theeuwes, J. (2004). Top-down search strategies cannot override attentional capture. Psychonomic Bulletin \& Review, 11, 65-70.

Theeuwes, J., \& Godijn, R. (2001). Attentional and oculomotor capture. In C. L. Folk \& B. S. Gibson (Eds.), Attraction, distraction and action: Multiple perspectives on attentional capture (pp. 121-150). Amsterdam: Elsevier.

Treat, J. R., Tumbas, N. S., McDonald, S. T., Shinar, D., Hume, R. D., Mayer, R. E., ... Castellan, N. J. (1979). Tri-level study of the causes of traffic accidents: Final report \& executive summary (Report No. DOT-HS-805-099). Washington, DC: NHTSA.

Vollrath, M., Briest, S., \& Drewes, J. (2006). Ableitung von Anforderungen an Fahrerassistenzsysteme aus Sicht der Verkehrssicherheit (Bericht der Bundesanstalt für Straßenwesen, Fahrzeugtechnik, Heft F 60). Bremerhaven: Wirtschaftsverlag NW.

Wierwille, W. W., \& Tijerina, L. (1995). Eine Analyse von Unfallberichten als ein Mittel zur Bestimmung von Problemen, die durch die Verteilung der visuellen Aufmerksamkeit und der visuellen Belastung innerhalb des Fahrzeugs verursacht werden. Zeitschrift für Verkehrssicherheit, 41, 164-168.

Wolkenstein, P. (2005). Der neue Audi Q7. Automobiltechnische Zeitschrift, 107, 958-967.
Woodson, W. E., \& Conover, D. W. (1964). Human engineering guide for equipment designers (2nd ed.). Berkeley: University of California Press.

Yantis, S. (1998). Control of visual attention. In H. Pashler (Ed.), attention (pp. 223-256). Hove: Psychology Press.

Yantis, S. (2000). Control of visual attention. In S. Monsell \& J. Driver (Eds.), Control of cognitive processes: Attention and performance XVIII (pp. 71-208). Cambridge: MIT Press.

Yantis, S., \& Egeth, H. E. (1999). On the distinction between visual salience and stimulus-driven attentional capture. Journal of Experimental Psychology: Human Perception and Performance, $25,661-676$.

Yantis, S., \& Hillstrom, A. P. (1994). Stimulus-driven attentional capture: Evidence from equiluminant visual objects. Journal of Experimental Psychology: Human Perception and Performance, 20, 95-107.

Yantis, S., \& Jonides, J. (1990). Abrupt visual onsets and selective attention: Voluntary versus automatic allocation. Journal of Experimental Psychology: Human Perception and Performance, $16,121-134$.

Yantis, S., \& Jonides, J. (1996). Attentional capture by abrupt onsets: New perceptual objects or visual masking? Journal of Experimental Psychology: Human Perception and Performance, 22, $1505-1513$. 